\title{
Covariation between behaviour and physiology indicators of coping style in zebrafish (Danio rerio)
}

\author{
Christian Tudorache', Marcel J M Schaaf' and Hans Slabbekoorn ${ }^{2}$ \\ Departments of ${ }^{1}$ Molecular Cell Biology and ${ }^{2}$ Behavioral Biology, Institute of Biology, Leiden University, \\ Sylviusweg 72, 2333 BE Leiden, The Netherlands
}

Correspondence should be addressed to $C$ Tudorache Email

c.tudorache@ biology.leidenuniv.nl

\begin{abstract}
All vertebrates exhibit physiological responses to a wide variety of stressors. The amplitude and profile of the response depend on the intensity, duration, controllability and predictability of the stressor, but there is also individual variation in the response, termed coping style. A better understanding of the expression of coping styles is of great value for medical applications, animal welfare issues and conservation. Here, we investigated the effect of repeated netting stress on proactive and reactive zebrafish (Danio rerio) as an upcoming model system for stress research. Fish were separated by coping styles according to the order of entering a novel environment. Subsequently, repeated netting stress was applied as stressor, over a period of 21 days. Full-body cortisol levels were determined at 0 , $15,30,60$ and $120 \mathrm{~min}$ after the last repeated stress event. Our results show that reactive fish display i) increased basal cortisol concentrations after being repeatedly stressed, ii) higher cortisol secretion over time and iii) slow recovery of cortisol concentration towards basal levels after the last repeated stress event. This study shows for the first time in zebrafish that different coping styles are associated with different cortisol responses during the recovery from stress over time and that coping styles can explain otherwise unaccounted variation in physiological stress responses.
\end{abstract}

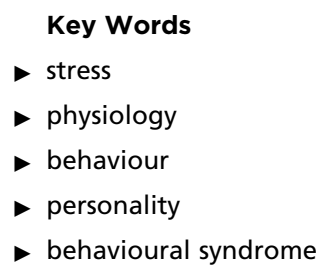

Journal of Endocrinology (2013) 219, 251-258

\section{Introduction}

All vertebrates exhibit physiological responses to stress, which are at the basis of appropriate behavioural adaptation. The amplitude and profile of these responses depend on the intensity, duration, controllability and predictability of the stressor (Kloet et al. 1998, Korte et al. 2005). The stressor-induced secretion of cortisol, arising from activation of the hypothalamus-pituitary-adrenal (HPA) axis (or hypothalamus-pituitary-interrenal (HPI) axis in fish), is a major index of stress level (Wendelaar Bonga 1997). Especially, long-term elevated levels of cortisol can cause a number of deleterious effects
(Pankhurst \& van der Kraak 2000, Schreck et al. 2001, Consten et al. 2002, Bernier et al. 2004), but there is a large degree of individual variation in this response.

Different individuals cope with exposure to stressors in different ways, which is an inherent feature of natural variation. The so-called stress coping styles are defined as a coherent set of individual behavioural and physiological differences that remain consistent across time and context (Koolhaas et al. 1999, Øverli et al. 2007). Other commonly used definitions, such as personalities (Gosling 2001), boldness (Dingemanse et al. 2007) or behavioural

Published by Bioscientifica Ltd. 
syndrome (Sih et al. 2004), refer to the same phenomenon but typically in the context of individual consistency in behaviour. Considering coping styles as continua of behavioural responses to external stressors, several behavioural axes have been recognized, among which the exploratory behaviour along a proactive-reactive continuum (Coleman \& Wilson 1998, Dingemanse et al. 2007, Reale et al. 2007, MacKenzie et al. 2009, Raoult et al. 2012). Variation along this continuum can affect survival and reproductive success (Carere et al. 2003, Carere \& van Oers 2004 ) and has been studied in a variety of fish species (e.g. Huntingford 1976, Coleman \& Wilson 1998, Schjolden et al. 2005, MacKenzie et al. 2009, Huntingford et al. 2010, Pavlidis et al. 2011, Raoult et al. 2012).

MacKenzie et al. (2009) showed that proactive and reactive common carp (Cyprinus carpio) responded oppositely to inflammatory challenge regarding $80 \%$ of investigated immune-related gene transcripts. Similarly, it has been repeatedly shown that there is a strong link between genetics, physiology and behaviour of stress coping in fishes (e.g. Sih et al. 2004, Øverli et al. 2007, MacKenzie et al. 2009). For example, individual rainbow trouts (Oncorhynchus mykiss) with low blood cortisol levels exhibit consistently different behavioural patterns, acclimating more rapidly to a novel environment, and being more likely to become socially dominant in pairing tests, than fish with high blood cortisol levels (Øverli et al. 2005). Interestingly, during such pairing tests in rats, the main difference between winning and losing a social interaction appears to be the speed of recovery of the stress hormone concentrations to baseline levels (Koolhaas et al. 2011). Consequently, we believe that individual variation in coping style, incorporated as an explanatory variable, could also account for unexplained variation in the stress response of zebrafish (Moretz et al. 2007, Norton \& Bally-Cuif 2012, Maximino et al. 2013).

Zebrafish (Danio rerio) have become an important model organism for neuropharmacological and behavioural research, and they are increasingly exploited for anxiety and stress research, as their genome, brain patterning, structure and function of neurochemical and behavioural systems show large similarities to those of terrestrial vertebrates, such as humans (for a review, see Steenbergen et al. (2011)). In zebrafish, the plateau of the stress response measured as full-body cortisol concentration is reached after about $15 \mathrm{~min}$ and recovery to baseline is accomplished after $60 \mathrm{~min}$, although with a considerable amount of individual variation in the data (Ramsay et al. 2006).
A better understanding of the endocrine stress response in terms of individual behaviour and stress coping styles can be useful for medical applications (e.g. Smith \& MacKenzie 2006, Boersma et al. 2011), animal welfare issues (e.g. Huntingford \& Adams 2005, Brown et al. 2009, Weiss et al. 2011) and conservation (e.g. Conrad et al. 2011, Vegvari et al. 2011, Gherardi et al. 2012). The objective of the current study, therefore, was to investigate the association between behavioural traits related to coping style, corticosteroid receptor expression and stressor-induced cortisol concentrations at different recovery time points after repeated stress, using the zebrafish as a model system.

\section{Materials and methods}

\section{Animals}

Zebrafish (D. rerio, ABTL, stock from Europet Bernina International BV, Gemert-Bakel, The Netherlands) were reared in densities of 12 individuals (male:female 1:1) per 7.51 tanks in standardised recirculation systems (Fleuren $\&$ Nooijen, Nederweert, The Netherlands; $14 \mathrm{~h}$ light:10 h darkness cycle; $24^{\circ} \mathrm{C}$ water temperature). Fish were fed daily with dry food (DuplaRinM, Gelsdorf, Germany) and frozen Artemias (Dutch Select Food, Aquadistri BV, Klundert, The Netherlands). Fish used in the experiment were $\sim 3.5$ months old. All experimental procedures were approved by the animal welfare committee of Leiden University (DEC\# 11023).

\section{Behavioural assay}

Behavioural indicators of coping styles were determined according to MacKenzie et al. (2009) and Huntingford et al. (2010). Briefly, we used a glass tank, consisting of a darkened holding compartment and an uncovered compartment, separated by a wall with a closable hatch. A total number of 100 adult zebrafish were transferred from their housing tank to the holding compartment. After acclimation for $5 \mathrm{~min}$, the trap door was opened so that fish could come out. Fish were divided into three approximately equally sized subgroups according to the order of emergence: first (defined as proactive coping style), intermediate (not used any further in this study) and last (defined as reactive coping style), based on the order they passed the hatch. This procedure was repeated until a stock of $\sim 140$ proactive and 140 reactive fish was created. Subsequent housing conditions were similar to rearing conditions, but with six fish per tank of both

Published by Bioscientifica Ltd. 
sexes and separated coping styles in duplicate, resulting in 12 fish per condition.

\section{Stress procedure}

We applied a netting stressor according to Ramsay et al. (2010). Briefly, fish were gently removed from the holding tank using a hand net $(11 \times 24 \mathrm{~cm})$. All six fish per tank were netted simultaneously, suspended in air for $3 \mathrm{~min}$, submerged in water for $3 \mathrm{~min}$ and suspended again for 3 min (Fig. 1). This stressor was applied once daily at different times of the day during a period of 21 days (repeatedly stressed) or only once (singularly stressed) before sampling (Fig. 1). We sampled all six fish per tank, from two different tanks (resulting in $n=12$ ) simultaneously before the experimental period (control), at $t=0$ (before netting), 15, 30, 60 and $120 \mathrm{~min}$ after the onset of the stressor. Fish were placed on blotting paper for a few seconds, subsequently placed in liquid nitrogen for $10 \mathrm{~s}$ and stored in plastic bags at $-80^{\circ} \mathrm{C}$ until full-body cortisol measurement.

\section{Full-body cortisol measurement}

Cortisol levels were measured according to a protocol previously described by Canavello et al. (2010). Briefly, frozen fish were weighed and pulverised in liquid nitrogen. Approximately half of the material was transferred to a bullet tube and weighed. Subsequently, $500 \mu \mathrm{l}$ ice-cold $1 \times$ PBS buffer was added and the samples were vortexed for $1 \mathrm{~min}$. Samples were split into three parts (allowing triplicate measurements) and each third of the sample volume $(\sim 300 \mu \mathrm{l})$ was transferred to separate bullet tubes. Subsequently, $1 \mathrm{ml}$ diethyl ether (BDH, Lutterworth, UK) was added to each new sample. Each sample was vortexed for $1 \mathrm{~min}$ and then centrifuged at $1370 \boldsymbol{g}$ for $5 \mathrm{~min}$. Following centrifugation, the organic layer of each sample containing cortisol was transferred to a separate test tube $(3 \times$ per sample for maximal cortisol extraction). Samples were kept overnight in the fume hood for evaporation of ether. The next day, determination of cortisol concentration was performed using an ELISA kit (Demetic Diagnostics GmbH, Kiel, Germany).

\section{$\mathrm{GR} \alpha, \mathrm{GR} \beta$ and MR expression}

The relative expression levels of GR $\alpha$ and GR $\beta$ were evaluated using qPCR according to Stockhammer et al. (2009). Briefly, five proactive and five reactive fish were killed immediately after separation according to coping style, in an overdose of clove oil ( $10 \%$ in ethanol, $>30 \%$ in water). The brains were dissected out, and brains and body were subsequently snap-frozen in liquid nitrogen for storage at $-80^{\circ} \mathrm{C}$. After thawing the samples in RNAlater, the tissue was homogenised in $1 \mathrm{ml}$ TRIzol reagent (Invitrogen), and subsequently, total RNA was extracted according to the manufacturer's instructions. cDNA synthesis reactions were performed in a $20 \mu \mathrm{l}$ mixture of $500 \mathrm{ng}$ RNA, $4 \mu \mathrm{l} 5 \times$ iScript reaction mix (Bio-Rad Laboratories) and $1 \mu \mathrm{l}$ iScript reverse transcriptase (Bio-Rad Laboratories). The reaction mixtures were incubated at $25^{\circ} \mathrm{C}$ for $5 \mathrm{~min}, 42^{\circ} \mathrm{C}$ for $30 \mathrm{~min}$ and $85^{\circ} \mathrm{C}$ for $5 \mathrm{~min}$.

(a)

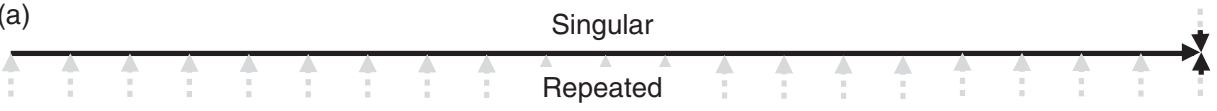

(b)

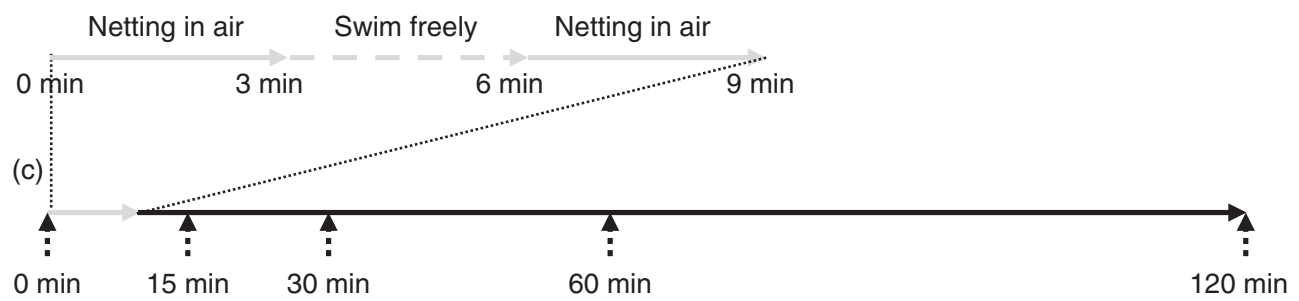

Figure 1

Time line of the stress paradigm applied in this study and the sampling time for cortisol measurements. (a) Netting stressor was applied once a day (grey) over the period of 21 days on random moments of the day in order to avoid adaptation to stressor (repeatedly stressed) or only once (singularly stressed) before sampling (grey and black). (b) Fish were netted in groups of 12 , suspended in air for 3 min (continuous line), submerged in water for $3 \mathrm{~min}$ (broken line) and suspended again for $3 \mathrm{~min}$ (continuous line). (c) Sampling occurred at $t=0 \mathrm{~min}$ (baseline) or at 15,30,60 and $120 \mathrm{~min}$ after the last stress event. http://joe.endocrinology-journals.org DOI: 10.1530/JOE-13-0225
(C) 2013 Society for Endocrinology Printed in Great Britain
Published by Bioscientifica Ltd. 
Real-time PCR was performed using the Chromo4 Realtime PCR detection system (Bio-Rad Laboratories) according to the manufacturer's instructions. Each reaction was performed in a $25 \mu \mathrm{l}$ volume comprising $1 \mu \mathrm{l}$ cDNA, $12.5 \mu \mathrm{l}$ $2 \times$ iQ SYBR Green Supermix (Bio-Rad Laboratories) and $10 \mathrm{pmol}$ of each primer. Cycling parameters were $95^{\circ} \mathrm{C}$ for $3 \mathrm{~min}$ to activate the polymerase followed by 40 cycles of $95^{\circ} \mathrm{C}$ for $15 \mathrm{~s}$ and $59^{\circ} \mathrm{C}$ for $45 \mathrm{~s}$. Fluorescence measurements were taken at the end of each cycle. Melting curve analysis was performed to verify that no primer dimers were amplified. All reactions were performed as technical triplicates. The primer sequences for $G R \alpha, G R \beta$ and $M R$ are as follows: forward and reverse, AACTGGCAACGGTTCTATCAGCTCA and TTCTGGTGAAAGAGCAGCGG; GATGAACTACGAATGTCTTA and GCAACAGACAGCCAGACAGCTCACT (Schaaf et al. 2008) and CCCATTGAGGACCAAATCAC and AGTAGAGCATTTGGGCGTTG (Alsop $\&$ Vijayan 2008) respectively. To test whether genomic sequences were amplified, a control with no reverse transcriptase was used (non-RT control). Results were analysed using the control-independent qPCR method. In short, the $C_{\mathrm{T}}$ value of the proactive samples was set at $100 \%$ and the difference between proactive and reactive $C_{\mathrm{T}}$ was calculated as $C_{\text {Tproactive }}-C_{\text {Treactive }}=\Delta C_{\mathrm{T}}$. Reactive relative expression was calculated as $100 / 2^{\Delta C_{\mathrm{T}}}$ and expressed in \%. Statistical analysis was performed on the raw $C_{\mathrm{T}}$ values.

\section{Statistical analyses}

Two-way ANOVA and Bonferroni post-hoc test were used to test statistically significant differences at $P<0.05$ with coping style as the independent variable and cortisol concentrations or relative expression levels as the dependent variable. All values are given as mean \pm s.E.M. All tests were conducted using SigmaStat 3.0 (Systat Software, Inc., San Jose, CA, USA).

\section{Results}

\section{Basal cortisol levels of proactive and reactive fish}

First, basal cortisol levels of proactive and reactive fish were assessed before the onset of the stress paradigm repetition of 21 days. These levels were not different between proactive and reactive fish (Table 1). Secondly, basal cortisol levels were measured again at $t=0$, i.e. before the start of the stressor (singularly stressed group) or at day 21 before the last stressor (repeatedly stressed group; Table 1 and Fig. 2). At this stage, reactive fish in the repeatedly stressed group showed $\sim 100 \%$ higher values than fish in the other three groups: proactive fish in the repeatedly stressed group and fish from both coping styles in the singularly stressed group (Table $1, P<0.05$ ).

\section{Stress-induced cortisol levels of proactive and reactive fish}

In addition, full-body cortisol concentrations were determined after the netting treatment for the different behaviourally determined coping styles, revealing considerable difference between the groups. All groups reached similar cortisol levels at 15 min after the netting treatment, but differences between coping styles and stress regimes were visible when comparing the subsequent downward slopes of the plots of full-body cortisol concentrations in ng/g against time in minutes (Fig. 2). In singularly and repeatedly stressed proactive fish, the recovery to baseline levels was already complete after $60 \mathrm{~min}$, while this took $120 \mathrm{~min}$ in reactive fish, both repeatedly and singularly stressed. The resulting regression patterns with the highest correlation coefficient $\left(r^{2}\right)$ varied with treatment and coping style. Proactive fish, both singularly and repeatedly stressed, showed an exponential decay, while singularly stressed reactive fish showed a linear decay over time. Decay in repeatedly stressed

Table 1 Control full-body cortisol concentrations before experimentation, baseline concentrations at $t=0$ at sampling and area under the curve resulting as a plot of cortisol concentrations over time (Fig. 3) in arbitrary units (AU) for proactive singularly, proactive fish repeatedly, reactive singularly and reactive repeatedly stressed fish

\section{Coping style \\ Stress regime}

Control concentration $(\mathrm{ng} / \mathrm{g})$ *

Baseline concentration $(t=0 ; \mathrm{ng} / \mathrm{g})$ *

Area under the curve $(\mathrm{AU})$

\begin{tabular}{cc}
\multicolumn{3}{c}{ Proactive } \\
\hline Singular & Repeated \\
\hline \multicolumn{2}{c}{$5.99 \pm 2.80^{\mathrm{a}} \pm 2.37^{\mathrm{a}}$} \\
775 & $\begin{array}{c}5.50 \pm 1.84^{\mathrm{a}} \\
846\end{array}$
\end{tabular}

*Superscript letters indicate significant differences between values (ANOVA, $P<0.05, n=6$, mean \pm s.E.M.).

\begin{tabular}{|c|c|}
\hline \multicolumn{2}{|c|}{ Reactive } \\
\hline Singular & Repeated \\
\hline \multicolumn{2}{|c|}{$6.66 \pm 2.21^{\mathrm{a}}$} \\
\hline $\begin{array}{c}6.66 \pm 1.63^{a} \\
1793\end{array}$ & $\begin{array}{c}12.99 \pm 1.88^{b} \\
2317\end{array}$ \\
\hline
\end{tabular}

http://joe.endocrinology-journals.org DOI: 10.1530/JOE-13-0225
๑) 2013 Society for Endocrinology Printed in Great Britain
Published by Bioscientifica Ltd. 


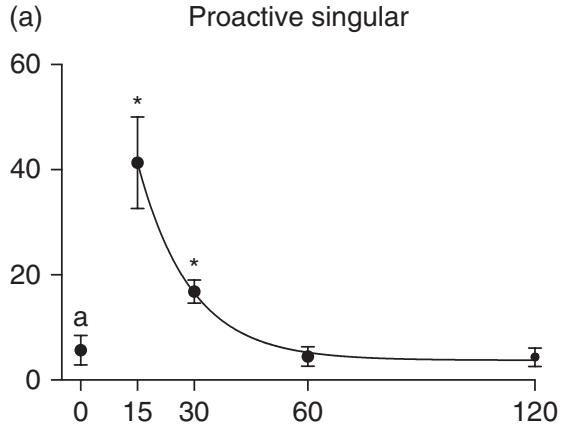

(b) Proactive repeated

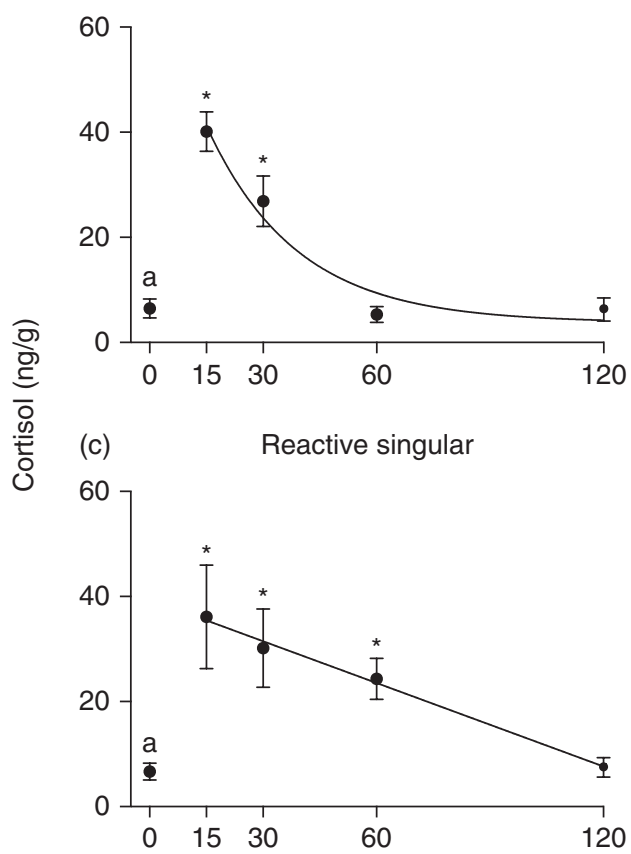

(d) Reactive repeated

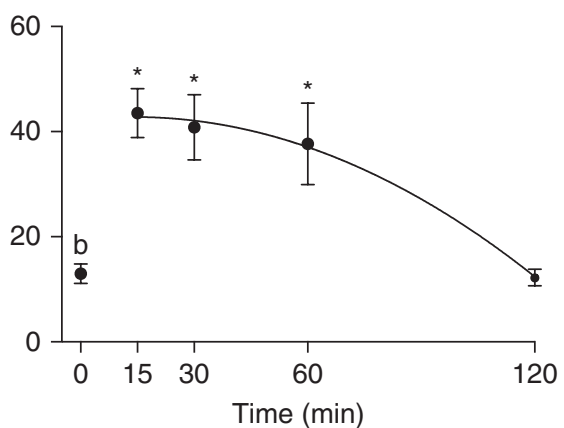

Figure 2

Full-body cortisol concentrations in $\mathrm{ng} / \mathrm{g}$ body weight over time in minutes after netting stress; (a) in proactive singularly, (b) in proactive repeatedly, (c) in reactive singularly and (d) in reactive repeatedly stressed fish. The $t=0$ data points indicate baseline values before the stress event. Values are mean \pm S.E.M., $n=6$. Letters indicate significant differences between, and * significant difference from baseline value. reactive fish followed a three-parameter power curve. The area under the curve is given in Table 1. Values in arbitrary units (AU) show that singularly stressed reactive fish display a 2.1- to 2.3-fold increase and repeatedly stressed reactive fish an increase of 2.7-2.9 times when compared with proactive fish.

\section{$M R, G R \alpha$ and $G R \beta$ expression of proactive and reactive fish}

In order to investigate whether different expression levels of GR $\alpha, G R \beta$ and MR may underlie the observed differences between proactive and reactive fish, absolute $C_{\mathrm{T}}$ values of reactive and proactive fish brain and the remaining body tissue were compared statistically with each other. There was no significant difference between coping styles or tissue $(P>0.05, n=6)$. The relative differences are shown in Fig. 3.

\section{Discussion}

This study shows that differences in the pattern of cortisol secretion during recovery from a physical stressor are associated with differences in behaviourally determined coping style. In reactive fish, the baseline cortisol levels were significantly elevated after a period of daily repeated stressors, which was not the case for proactive fish. Peak cortisol levels measured at $15 \mathrm{~min}$ after the stressor did not vary among coping styles and stress regimes. However, the shape of the recovery phase of the cortisol response curves varied considerably. Proactive fish returned to baseline levels after $60 \mathrm{~min}$, while reactive fish had reached full recovery only after $120 \mathrm{~min}$. The area under the curve (reflecting the total amount of cortisol) showed similar low values in proactive fish but a twofold increase in singularly stressed and a threefold increase in repeatedly stressed reactive fish. The full-body baseline and control cortisol levels presented here are consistent with previous studies on stress response in zebrafish, as were peak levels after 15 min (Ramsay et al. 2006, 2010). This consistency in peak cortisol levels suggests a general physiological response to strong physical stressors independent of coping style, while only after repeated exposure to stressors significant variation in cortisol levels emerges that is strongly dependent on coping style.

Our results show that recovery phase of the cortisol response curves after stress differs greatly between coping styles (as assessed by separating fish based on a behavioural assay of emergence into the open from a smaller enclosure). The exponential decline curves in proactive

Published by Bioscientifica Ltd 


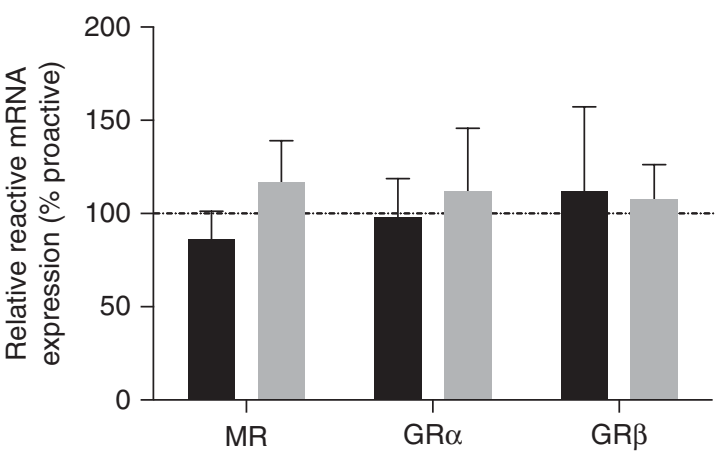

Figure 3

Relative difference in control-independent qPCR mRNA expression of mineralocorticoid receptor (MR), glucocorticoid receptor $\alpha(\mathrm{GR} \alpha)$ and glucocorticoid receptor $\beta$ (GR $\beta$ ) in brain (black) and body (grey) tissue. The bars indicate the relative expression in reactive fish in $\%$ proactive expression, with proactive expression set to $100 \%$ (line). Values are mean \pm s.E.M., $n=5$. Statistical analysis was done on raw $C_{T}$ values. There is no significant difference between coping style and tissues $(P>0.05)$.

fish of both stress regimes could be explained by a general binding rate model for hormones (Schmidt-Nielsen 1997). The linear and the power decline curve of singularly and repeatedly stressed reactive fish, respectively, could be explained by a cortisol production for a longer period in reactive compared with proactive fish or the interaction of cortisol reduction processes, possibly due to differences in the negative feedback mechanism of the HPI axis. However, the results show that relative expression levels of $\alpha$ and $\beta$ glucocorticoid and mineralocorticoid receptors were not different between coping styles or between tissues tested. This finding contradicts the results by Johansen et al. (2011) who reported increased mineralocorticoid receptors' expression in low responding (LR), compared with high responding (HR) rainbow trout. However, the differences may be explained by the applied protocol: the study by Johansen et al. (2011) analysed different parts of the brain, such as cerebellum, hypothalamus, optic tectum and telencephalon, while this study examined the entire brain. Additionally, Øverli et al. (2007) suggest that HR and LR fish do not always correlate with behaviourally determined reactive and proactive fish, respectively, possibly due to other factors currently not fully understood. A possible explanation could be the nature of artificial selection of strains used in aquaculture, which can yield a distribution of coping styles that is quite different from natural fish populations. In addition, the segregation of individuals based on coping styles may depend to some extent on the specific behavioural assay of choice.
Our use of descriptive models, a method adopted from ecological studies (Mangel \& Clark 1989), has proven to be a suitable tool to reveal patterns that suggest divergent physiological processes among individuals of different coping style. This method is supported by the additional analysis of the areas under the curves, which also differed with coping style and stress regime. The variation in curves among coping style and exposure regime groups allows some speculation about underlying processes, but more studies are needed to get a better understanding of the consistency and physiological basis of these patterns.

Chronically elevated baseline cortisol levels due to repeated stressors can lead to a variety of negative physiological and behavioural effects on the individual, such as a reduction in foraging behaviour, a decrease in body weight or a disruption of the immune response (Koolhaas et al. 2011). Consequently, stress may reduce reproductive success (Schreck et al. 2001) and disrupt trophic interactions (Archard et al. 2012), from which it follows that stress may not only negatively affect individuals but also contribute to population decline and the possible extinction of species (Schaaf et al. 2008). Nevertheless, natural populations typically consist of individuals of a range of different copying styles and such a mixture means that individuals will vary in how well they fare under stressful situations but also provides a population with some flexibility to persist (Koolhaas et al. 1999, Korte et al. 2005). Similarly, studies on sticklebacks (Gasterosteus aculeatus) have revealed a personalitydependent predation risk (Bell \& Sih 2007) and personality distribution in natural lakes determined by the presence of a large natural predator (Dingemanse et al. 2007). Also for this particularly strong selection pressure, the presence of a mixture of coping styles allows a variable subset of individuals to survive and therefore populations to persist under various predation regimes. Consequently, we argue that understanding the impact of stressors on a particular species requires the analysis of individuals of divergent phenotype. Mean values for a population may correctly reflect the stress physiology of only few individuals and may lead to misunderstandings about individuals of extreme coping style (which may be critical for medical cases in humans) and about population developments (which may be critical for applications in conservation).

In conclusion, this study stresses the value of taking coping styles into account when using the zebrafish as a model system in stress research. Our data show that behavioural aspects of different coping styles are associated with different cortisol responses after stress. Given the popularity and versatility of the zebrafish as a model in

Published by Bioscientifica Ltd. 
biomedical research, this indicates that there will be plenty of opportunity to study molecular mechanisms underlying this association. We expect that such studies will contribute significantly to our insights into the potential impact of behavioural and physiological aspects of coping styles on individual fitness.

\section{Declaration of interest}

The authors declare that there is no conflict of interest that could be perceived as prejudicing the impartiality of the research reported.

\section{Funding}

C Tudorache was supported by an NWO-STW funded VENI-fellowship (\#11731).

\section{Acknowledgements}

The authors would like to acknowledge the technical support of Davy de Witt and the helpful discussions with Herman Spaink and Peter Steenbergen. Gratitude is extended to Danielle Champagne and Gert Flik for their help on the manuscript and Vanesa Jimenez and Erica Benard for helping with the qPCR work.

\section{References}

Alsop D \& Vijayan MM 2008 Development of the corticosteroid stress axis and receptor expression in zebrafish. American Journal of Physiology. Regulatory, Integrative and Comparative Physiology 294 R711-R719. (doi:10.1152/ajpregu.00671.2007)

Archard GA, Earley RL, Hanninen AF \& Braithwaite B 2012 Correlated behaviour and stress physiology in fish exposed to different levels of predation pressure. Functional Ecology 26 637-645. (doi:10.1111/ j.1365-2435.2012.01968.x)

Bell AM \& Sih A 2007 Exposure to predation generates personality in threespined sticklebacks (Gasterosteus aculeatus). Ecology Letters 10 828-834. (doi:10.1111/j.1461-0248.2007.01081.x)

Bernier NJ, Bedard N \& Peter RE 2004 Effects of cortisol on food intake, growth, and forebrain neuropeptide $\mathrm{Y}$ and corticotropin-releasing factor gene expression in goldfish. General and Comparative Endocrinology 135 230-240. (doi:10.1016/j.ygcen.2003.09.016)

Boersma GJ, Benthem L, van Beek AP, van Dijk G \& Scheurink AJW 2011 Personality, a key factor in personalized medicine? European Journal of Pharmacology 667 23-25. (doi:10.1016/j.ejphar.2011.05.079)

Brown JA, Dewey C, Delange CFM, Mandell IB, Purslow PP, Robinson JA, Squires EJ \& Widowski TM 2009 Reliability of temperament tests on finishing pigs in group-housing and comparison to social tests. Applied Animal Behaviour Science 118 28-35. (doi:10.1016/j.applanim. 2009.02.005)

Canavello PR, Jonathan MC, Beeson E, Laffoon AL, Grimes C, Haymore W, Elegante MF, Bartels BK, Hart PC, Elkhayat SI et al. 2010 Measuring endocrine (cortisol) responses of zebrafish to stress. In Zebrafish Neurobehavioral Protocols, pp 135-142. Eds AV Kalueff \& JM Cachat. New York: Springer.

Carere C \& van Oers K 2004 Shy and bold great tits (Parus major): body temperature and breath rate in response to handling stress. Physiology \& Behavior 82 905-912.

Carere C, Groothuis TGG, Mostl E, Daan S \& Koolhaas JM 2003 Faecal corticosteroids in a territorial bird selected for different personalities: http://joe.endocrinology-journals.org DOI: $10.1530 / J O E-13-0225$
() 2013 Society for Endocrinology Printed in Great Britain daily rhythm and the response to social stress. Hormones and Behavior 43 540-548. (doi:10.1016/S0018-506X(03)00065-5)

Coleman K \& Wilson DS 1998 Shyness and boldness in pumpkinseed sunfish: individual differences are context-specific. Animal Behaviour $\mathbf{5 6}$ 927-936. (doi:10.1006/anbe.1998.0852)

Conrad JL, Weinersmith KL, Brodin T, Saltz JB \& Sih A 2011 Behavioural syndromes in fishes: a review with implications for ecology and fisheries management. Journal of Fish Biology 78 395-435. (doi:10.1111/ j.1095-8649.2010.02874.x)

Consten D, Lambert JGD, Komen H \& Goos HJT 2002 Corticosteroids affect the testicular androgen production in male common carp (Cyprinus carpio L.). Biology of Reproduction 66 106-111. (doi:10.1095/ biolreprod66.1.106)

Dingemanse NJ, Wright J, Kazem AJN, Thomas DK, Hickling R \& Dawnay N 2007 Behavioural syndromes differ predictably between 12 populations of three-spined stickleback. Journal of Animal Ecology 76 1128-1138. (doi:10.1111/j.1365-2656.2007.01284.x)

Gherardi F, Aquiloni L \& Tricarico E 2012 Behavioral plasticity, behavioral syndromes and animal personality in crustacean decapods: an imperfect map is better than no map. Current Zoology 58 567-579.

Gosling SD 2001 From mice to men: what can we learn about personality from animal research? Psychological Bulletin 127 45-86. (doi:10.1037) 0033-2909.127.1.45)

Huntingford FA 1976 Relationship between anti-predator behavior and aggression among conspecifics in 3-spined stickleback, Gasterosteus aculeatus. Animal Behaviour 24 245-260. (doi:10.1016/ S0003-3472(76)80034-6)

Huntingford F \& Adams C 2005 Behavioural syndromes in farmed fish: implications for production and welfare. Behaviour 142 1207-1221. (doi:10.1163/156853905774539382)

Huntingford FA, Andrew G, Mackenzie S, Morera D, Coyle SM, Pilarczyk M \& Kadri S 2010 Coping strategies in a strongly schooling fish, the common carp Cyprinus carpio. Journal of Fish Biology 76 1576-1591. (doi:10.1111/j.1095-8649.2010.02582.x)

Johansen IB, Sandvik GK, Nilsson GE, Bakken M \& Øverli Ø 2011 Cortisol receptor expression differs in the brains of rainbow trout selected for divergent cortisol responses. Comparative Biochemistry and Physiology, Part D 6 126-132. (doi:10.1016/j.cbd.2010.11.002)

Kloet ER, Vreugdenhil E, Oitzl MS \& Joels M 1998 Brain corticosteroid receptor balance in health and disease. Endocrine Reviews 19 269-301. (doi:10.1210/er.19.3.269)

Koolhaas JM, Korte SM, De Boer SF, Van Der Vegt BJ, Van Reenen CG, Hopster H, De Jong IC, Ruis MAW \& Blokhuis HJ 1999 Coping styles in animals: current status in behavior and stress-physiology. Neuroscience and Biobehavioral Reviews 23 925-935.

Koolhaas JM, Bartolomucci A, Buwalda B, de Boer SF, Flügge G, Korte SM, Meerlo P, Murison R, Olivier B, Palanza P et al. 2011 Stress revisited: a critical evaluation of the stress concept. Neuroscience and Biobehavioral Reviews 35 1291-1301. (doi:10.1016/j.neubiorev.2011.02.003)

Korte M, Koolhaas JM, Wingfield JC \& McEwen BJ 2005 The Darwinian concept of stress: benefits of allostasis and costs of allostatic load and the trade-offs in health and disease. Neuroscience and Biobehavioral Reviews 29 3-38. (doi:10.1016/j.neubiorev.2004.08.009)

MacKenzie S, Ribas L, Pilarczyk M, Capdevila DM, Kadri S \& Huntingford FA 2009 Screening for coping style increases the power of gene expression studies. PLOS ONE 4 e5314. (doi:10.1371/journal.pone. 0005314)

Mangel M \& Clark CW 1989 Dynamic Modeling in Behavioral Ecology, pp 58-63. Princeton, NJ, USA: Princeton University Press.

Maximino C, Puty B, Matos Oliveira KR \& Herculano AM 2013 Behavioral and neurochemical changes in the zebrafish leopard strain. Genes, Brain and Behavior 12 576-582.

Moretz JA, Martins EP \& Robison BD 2007 Behavioral syndromes and the evolution of correlated behavior in zebrafish. Behavioral Ecology 18 556-556. (doi:10.1093/beheco/arm011) 
Norton WHJ \& Bally-Cuif J 2012 Unravelling the proximate causes of the aggression-boldness behavioural syndrome in zebrafish. Behaviour 149 1063-1079. (doi:10.1163/1568539X-00003012)

Øverli Ø, Winberg S \& Pottinger TG 2005 Behavioral and neuroendocrine correlates of selection for stress responsiveness in rainbow trout - a review. Integrative and Comparative Biology 45 463-474. (doi:10.1093/ icb/45.3.463)

Øverli Ø, Sorensen C, Pulman KGT, Pottinger TG, Korzan WJ, Summers CH \& Nilsson GE 2007 Evolutionary background for stress-coping styles: relationships between physiological, behavioral, and cognitive traits in non-mammalian vertebrates. Neuroscience and Biobehavioral Reviews $\mathbf{3 1}$ 396-412. (doi:10.1016/j.neubiorev.2006.10.006)

Pankhurst NW \& van der Kraak G 2000 Evidence that acute stress inhibits ovarian steroidogenesis in rainbow trout in vivo, through the action of cortisol. General and Comparative Endocrinology 117 225-237. (doi:10.1006/gcen.1999.7401)

Pavlidis M, Sundvika M, Chena Y \& Panulaa P 2011 Adaptive changes in zebrafish brain in dominant-subordinate behavioral context. Behavioural Brain Research 225 529-537. (doi:10.1016/j.bbr.2011. 08.022)

Ramsay JM, Feist GW, Varga ZM, Westerfield M, Kent ML \& Schreck CB 2006 Whole-body cortisol is an indicator of crowding stress in adult zebrafish, Danio rerio. Aquaculture 258 565-574. (doi:10.1016/ j.aquaculture.2006.04.020)

Ramsay JM, Feist GW, Varga ZM, Westerfield M, Kent ML \& Schreck CB 2010 Whole-body cortisol response of zebrafish to acute net handling stress. Aquaculture 297 157-162. (doi:10.1016/j.aquaculture. 2009.08.035)

Raoult V, Brown C, Zuberi A \& Williamson JE 2012 Blood cortisol concentrations predict boldness in juvenile mulloway (Argyosomus japonicus). Journal of Ethology 30 225-232. (doi:10.1007/ s10164-011-0314-9)

Reale D, Reader SM, Sol D, McDougall PT \& Dingemanse NJ 2007 Integrating animal temperament within ecology and evolution.
Biological Reviews 82 291-318. (doi:10.1111/j.1469-185X. 2007.00010.x)

Schaaf MJM, Chatzpoulou A \& Spaink HP 2008 The zebrafish as a model system for glucocorticoid receptor research. Comparative Biochemistry and Physiology, Part A 153 75-82. (doi:10.1016/j.cbpa.2008.12.014)

Schjolden J, Stoskhus A \& Winberg S 2005 Does individual variation in stress responses and agonistic behavior reflect divergent stress coping strategies in juvenile rainbow trout? Physiological and Biochemical Zoology 78 715-723. (doi:10.1086/432153)

Schmidt-Nielsen K 1997 Animal physiology: adaptation and environment, 5th edn, pp 194-529. Cambridge, UK: Cambridge University Press.

Schreck CB, Contreras-Sanchez W \& Fitzpatrick MS 2001 Effects of stress on fish reproduction, gamete quality, and progeny. Aquaculture 197 3-24. (doi:10.1016/S0044-8486(01)00580-4)

Sih A, Bell AM, Johnson JC \& Ziemba RE 2004 Behavioral syndromes: an integrative overview. Quarterly Review of Biology 79 241-277.

Smith TW \& MacKenzie J 2006 Personality and risk of physical illness. Annual Review of Clinical Psychology 2 435-467. (doi:10.1146/annurev. clinpsy.2.022305.095257)

Steenbergen PJ, Richardson MK \& Champagne DL 2011 The use of the zebrafish model in stress research. Progress in Neuro-Psychopharmacology \& Biological Psychiatry 35 1432-1451. (doi:10.1016/j.pnpbp.2010. 10.010)

Stockhammer OW, Zakrzewska A, Hegedûs Z, Spaink HP \& Meijer AH 2009 Transcriptome profiling and functional analyses of the zebrafish embryonic innate immune response to salmonella infection. Journal of Immunology 182 5641-5653. (doi:10.4049/jimmunol.0900082)

Vegvari Z, Barta Z, Mustakallio P \& Szekely T 2011 Consistent avoidance of human disturbance over large geographical distances by a migratory bird. Biology Letters 7 814-817. (doi:10.1098/rsbl.2011.0295)

Weiss A, Adams MJ \& King JE 2011 Happy orang-utans live longer lives. Biology Letters 7 872-874. (doi:10.1098/rsbl.2011.0543)

Wendelaar Bonga SE 1997 The stress response in fish. Physiological Reviews 77 591-625.

Received in final form 30 August 2013

Accepted 27 September 2013
(C) 2013 Society for Endocrinology Printed in Great Britain 